\title{
Peak expiratory flow rates before and after exercise in schoolchildren
}

\author{
M. L. BURR, B. A. ELDRIDGE, and L. K. BORYSIEWICZ \\ From the M.R.C. Epidemiology Unit, and Welsh National School of Medicine, Cardiff
}

\begin{abstract}
Burr, M. L., Eldridge, B. A., and Borysiewicz, L. K. (1974). Archives of Disease in Childhood, 49, 923. Peak expiratory flow rates before and after exercise in schoolchildren. Peak expiratory flow rates (PEFR) were measured before and after 6 minutes' exercise in 12-year-old schoolchildren living in two areas. In boys, but not in girls, the mean initial PEFR was lower in asthmatics than in nonasthmatics. After exercise, children with current asthma tended to show a marked fall in PEFR. Children with a history of wheezing, atopic disease, or a first-degree asthmatic relative showed something of the same tendency, though their responses to exercise largely overlapped those of the control group.

The unknown mechanism causing exercise-induced asthma appears to operate also in some subjects who show features related to asthma, but not in the rest of the child population.
\end{abstract}

Asthmatic children are known to develop airways obstruction after exercise (Jones, Buston, and Wharton, 1962). Free-range running has been shown to be the most effective method of producing this effect, which occurs after about 6 minutes' exercise and reaches its peak 3 to 5 minutes later (Anderson, Connolly, and Godfrey, 1971). Since nonasthmatic children do not seem to react in this way, the effect of exercise on ventilatory function is thought to be highly specific of asthma (Fitch and Morton, 1971). The discriminatory value of the test has been uncertain, however, since hitherto it has been studied only in selected groups of asthmatic and nonasthmatic children. This paper presents peak expiratory flow rates (PEFR) before and after exercise in a population of schoolchildren.

\section{Subjects and methods}

The population was geographically defined by the catchment areas of two local authority comprehensive schools. One was in a residential suburb of Cardiff while the other was an area of Glamorgan, which is partly rural and partly industrial. The subjects were all children living in these areas who were in their first year at local authority-controlled schools, i.e. their twelfth birthday occurred during the school year September 1972 to August 1973. They were all seen during the

Received 29 April 1974. summer term of 1973 . In addition to the 2 comprehensive schools, 5 other state-controlled schools were involved in the study since they received some children living in the area concerned and in the same age group. No children from the specified population were attending schools for the physically handicapped or receiving home tuition at the time, and mentally subnormal children were excluded from the survey. One child was permanently in hospital for a malignant condition and was not included in the study.

A questionnaire relating to chest illnesses and symptoms was completed by the parents of each child and included questions asking whether the child had ever suffered from asthma, eczema, or hay fever, whether there was a history of asthma in any close relatives (parents, brothers, or sisters), and whether the child had ever wheezed, and if so, if this had occurred during the past 12 months. In a pilot study the word 'wheeze' was found to be sometimes misunderstood, so a definition was inserted and the question read, 'Has a wheeze-that is, a whistling noise (high or low-pitched)—ever been heard coming from your child's chest?'

The children were seen in groups and the PEFR measured by the same observer. The subjects were exercised by running in an enclosed space (the school hall or gymnasium); they started off at over 7 m.p.h. (11 $\mathrm{km} / \mathrm{hr}$ ) and then adjusted their speed to their own ability. After 6 minutes of continuous exercise each child was called back to sit down for 5 minutes, and a second PEFR was then recorded without reference to the initial reading or to the questionnaire. On each occasion five measurements were obtained and the mean of the three highest 
readings taken as the actual value. Heights and weights of the children were also recorded.

At the time of the exercise 6 children had taken medication for asthma during the previous 5 hours. Since this may have affected their response, they were exercised again on a subsequent occasion when they had been without medication for at least 5 hours, and the exercise-effect calculated from the results obtained at that time.

\section{Results}

The parents of one boy refused permission for him to take part in the survey because of his current asthma. 817 children ( 410 boys, 407 girls) were seen and gave an initial PEFR. 4 children were unable to run owing to orthopaedic conditions, and one child would not co-operate for the second test, so that a postexercise PEFR was obtained for $\mathbf{8 1 2}$ children (409 boys, 403 girls).

Children were considered to have current asthma when their parents stated that they had had the disease and had wheezed during the past 12 months. There were 22 boys and 11 girls in this group; if the one nonresponding asthmatic boy is added, the prevalence-rate was $4 \cdot 2 \%(5 \cdot 6 \%$ boys, $2 \cdot 7 \%$ girls $)$.

Table I shows the mean resting PEFR in the asthmatics and nonasthmatics. The asthmatic boys had lower rates than those without asthma $(\mathrm{P}<0.01)$, whereas the asthmatic and nonasthmatic girls had the same mean PEFR. In both sexes the asthmatics and nonasthmatics had comparable heights and weights. The regression equations of PEFR on height in the nonasthmatic subjects were as follows. boys.

PEFR $(1 . / \mathrm{min})=2.97 \times$ height $(\mathrm{cm})-110.6$ in girls.

PEFR $(1 . / \mathrm{min})=3.43 \times$ height $(\mathrm{cm})-178.2$ in

$(\mathrm{P}<0.001$ in each case).
The nonasthmatic children were further subdivided on the basis of their parents' answers to the questionnaire, so that the following 6 groups resulted.

(1) Current asthmatics (defined above).

(2) Other current wheezers, i.e. wheezing during the past 12 months but parents denied 'asthma'.

(3) Ex-wheezers, i.e. wheezing at some time but not in the past 12 months.

(4) Others with atopic history, i.e. never wheezed, but a history of eczema or hay fever.

(5) Others with family history, i.e. not in above groups, but with a first-degree asthmatic relative.

(6) All other children.

The 5 children for whom no postexercise PEFR was obtained all belonged to group 6 .

The change in PEFR consequent upon exercise was expressed as the ratio (PEFR2/PEFR1) $\times 100$, so that a ratio below 100 represents a fall. Table II shows the distribution of this ratio in the 6 groups of children. The mean ratios for boys and girls were not significantly different within any group, so they are combined. When the mean ratios of the first 5 groups are compared with that of the sixth group, significant differences emerge for current asthmatics, other current wheezers $(P<0.001)$, ex-wheezers, and others with an atopic history $(P<0 \cdot 05)$. The children whose family history was their only distinguishing feature (group 5) had a mean ratio of $96 \cdot 0$, which is not significantly different from that of group 6. Since each child appears only once in Table II, there are of course several children with a family history of asthma who are included in the first 4 groups.

The children with no relevant history are the only group for whom the distribution of this ratio is not skewed towards lower values. The variance of the ratio is least in these children, and the distribution

TABLE I

Resting PEFR, heights, and weights of asthmatic and nonasthmatic children

\begin{tabular}{|c|c|c|c|c|}
\hline & \multicolumn{2}{|c|}{ Boys } & \multicolumn{2}{|c|}{ Girls } \\
\hline & Asthmatics & Nonasthmatics & Asthmatics & Nonasthmatics \\
\hline $\begin{array}{l}\text { No. } \\
\text { PEFR }(1 . / \mathrm{min}) \\
\text { Mean } \\
\text { SE } \\
\text { Height }(\mathrm{cm}) \\
\text { Mean } \\
\text { SE } \\
\text { Weight (kg) } \\
\text { Mean } \\
\text { SE }\end{array}$ & $\begin{array}{r}22 \\
295 \\
11 \\
147 \cdot 8 \\
1 \cdot 8 \\
40 \cdot 8 \\
2 \cdot 0\end{array}$ & $\begin{array}{r}389 \\
332 \\
3 \\
149 \cdot 1 \\
0 \cdot 4 \\
\\
40 \cdot 5 \\
0 \cdot 4\end{array}$ & $\begin{array}{r}11 \\
337 \\
17 \\
150 \cdot 4 \\
2 \cdot 0 \\
43 \cdot 5 \\
2 \cdot 4\end{array}$ & $\begin{array}{r}395 \\
337 \\
3 \\
150 \cdot 0 \\
0.4 \\
41 \cdot 8 \\
0.5\end{array}$ \\
\hline
\end{tabular}


TABLE II

Changes in PEFR after exercise

\begin{tabular}{|c|c|c|c|c|c|c|c|}
\hline$($ PEFR2/PEFR1) $\times 100$ & $\begin{array}{c}\text { Current } \\
\text { asthmatics }\end{array}$ & $\begin{array}{l}\text { Other current } \\
\text { wheezers }\end{array}$ & Ex-wheezers & $\begin{array}{l}\text { Others with } \\
\text { atopic history }\end{array}$ & $\begin{array}{l}\text { Others with } \\
\text { family history }\end{array}$ & All others & Totals \\
\hline $\begin{array}{l}120-125 \\
115- \\
110- \\
105- \\
100- \\
95- \\
90- \\
85- \\
80- \\
75- \\
70- \\
65- \\
60- \\
55- \\
50- \\
45- \\
40- \\
35- \\
30-\end{array}$ & $\begin{array}{l}3 \\
7 \\
5 \\
7 \\
1 \\
1 \\
2 \\
3 \\
1 \\
1 \\
1\end{array}$ & $\begin{array}{r}1 \\
2 \\
7 \\
14 \\
7 \\
9 \\
3 \\
4 \\
1\end{array}$ & $\begin{array}{r}1 \\
2 \\
11 \\
19 \\
15 \\
4 \\
4\end{array}$ & $\begin{array}{r}1 \\
1 \\
2 \\
10 \\
20 \\
19 \\
7 \\
5 \\
1 \\
1\end{array}$ & $\begin{array}{r}1 \\
3 \\
15 \\
15 \\
18 \\
2 \\
3 \\
\\
1 \\
1\end{array}$ & $\begin{array}{r}2 \\
4 \\
4 \\
46 \\
115 \\
215 \\
120 \\
30 \\
7 \\
3 \\
2\end{array}$ & $\begin{array}{r}3 \\
4 \\
8 \\
55 \\
158 \\
286 \\
186 \\
57 \\
29 \\
9 \\
4 \\
4 \\
4 \\
1 \\
1 \\
1 \\
1 \\
1\end{array}$ \\
\hline Total & 33 & 49 & 56 & 67 & 59 & 548 & 812 \\
\hline $\begin{array}{l}\text { Mean ratio } \\
\text { SD }\end{array}$ & $\begin{array}{l}79 \cdot 5 \\
15 \cdot 6\end{array}$ & $\begin{array}{l}92 \cdot 0 \\
11 \cdot 3\end{array}$ & $\begin{array}{r}95 \cdot 4 \\
6 \cdot 5\end{array}$ & $\begin{array}{r}95 \cdot 0 \\
8 \cdot 0\end{array}$ & $\begin{array}{r}96 \cdot 0 \\
8 \cdot 3\end{array}$ & $\begin{array}{r}97 \cdot 5 \\
6 \cdot 1\end{array}$ & $\begin{array}{r}96 \cdot 0 \\
8 \cdot 3\end{array}$ \\
\hline
\end{tabular}

was very symmetrical around a mean of 97.5 , representing a slight fall in mean PEFR after exercise.

\section{Discussion}

The survey was limited to children living in a specified area, within a single year of age, and attending state schools, other than the mentally subnormal. Only one child in the study population was not seen, giving a response rate of $99.9 \%$, so that further selective bias was avoided.

The initial PEFRs of nonasthmatic boys and girls were comparable with each other and with those of asthmatic girls. The asthmatic boys had a lower mean value, however, which could not be explained by a difference in body-size since their heights and weights were similar to those of the nonasthmatics. Thus, whereas the asthmatic girls were not affected by their disease at rest, in the boys it appeared to depress the mean PEFR. This could be due either to a constant degree of airways obstruction or to a greater instability of the disease. The findings confirm previous reports that asthma tends to be more severe (as well as more common) in boys than in girls (Dawson et al., 1969).

Regression equations of PEFR on height are often used to calculate 'predicted PEFR' values. The equations obtained in this study are quoted as a means of obtaining predicted values for nonasthmatic 12 year olds; they cannot be compared directly with those from surveys involving children in wider age groups.

The effect of exercise on airways resistance in asthmatics has been documented in several studies (Jones et al., 1962; McNeill et al., 1966; Fitch and Morton, 1971). It has been suggested as a basis for diagnosis as it is said to be a constant feature of the disease (Jones, Wharton, and Buston, 1963). In general these studies have been performed on children attending hospital, who tend to be the more severe cases of the disease. Furthermore, controls have usually been small selected groups of children. It has therefore been uncertain what the exercise response is in milder asthmatics and in the child population as a whole.

This survey confirms previous findings of an effect of exercise on lung-function in currently asthmatic children. On average, their PEFR fell substantially more than those of children with no relevant history, though some overlap occurred. It may be objected that the diagnosis was unsatisfactory, being based on the parents' statements that their children had the disease. The prevalence rates and sex ratio were similar to those reported from several other recent surveys, however, summarized by Williams and McNicol (1969), so that it seems unlikely that serious error has arisen in this way.

In any consideration of a disease which is thought to be clearly demarcated from the unaffected 
'normal' condition, interest naturally focuses on groups of persons who may show intermediate features. 'Wheezy bronchitis' was considered by Williams and McNicol (1969) to be basically the same disorder as asthma in that both conditions tend to be associated with the same related factors. This view was supported from the findings of König, Godfrey, and Abrahamov (1972) that children with a history of wheezy bronchitis tend to have exerciseinduced bronchospasm. Furthermore, increased bronchial lability has been reported in subjects with only a past history of asthma (Jones and Jones, 1966). The present survey confirms these observations in that 'current wheezers' not said to have asthma, and to a lesser extent ex-wheezers, tend to develop a greater fall in PEFR after exercise than the control group.

Asthma is regarded as often being a manifestation of an atopic tendency, so it seems reasonable to regard children who have had eczema or hay fever as a possible intermediate group. Such children again had a greater mean fall in PEFR than the control group. It therefore seems that, even among children who have never wheezed, an atopic history may be associated with the same disorder which in the overt asthmatic manifests itself as exerciseinduced asthma.

König and Godfrey (1973) also reported increased exercise-induced bronchial lability in the families of asthmatic children. In the present study children with only a family history of asthma had a slightly greater mean fall in PEFR than the control group, but the difference was not statistically significant. The group excludes the wheezy and atopic children, however, in whom a familial tendency to asthma might be more likely to be found.

The distribution of the ratio (PEFR2/PEFR1) $\times 100$ shows some interesting features when different groups of subjects are compared. The current asthmatics were markedly different from the other groups in that the distribution was displaced downwards and was very wide and skewed. In each of the other groups the distribution was similar to that of the control group, except for a negative skew, representing some children with a marked fall in PEFR. The children with no relevant history showed a remarkably symmetrical distribution, which was more compact than that of any other group. Unlike the skewed distributions of the other groups, this could be explained by the scatter resulting from physiological variation and the inaccuracies of the testing procedure.

Thus, the unknown mechanism which causes asthmatics to develop airways obstruction after exercise apparently exists in some children with a history of wheezing or atopic disease, or a firstdegree asthmatic relative. The remainder of the child population does not seem to show this effect, it being very uncommon for as much as a $15 \%$ fall in PEFR to occur after exercise in these children.

We are grateful for the help of Drs. D. J. Anderson and C. J. Revington, Principal School Medical Officers for Cardiff and Glamorgan, in carrying out this survey. We also thank Mr. D. J. Hole and Mr. P. M. Sweetnam for statistical help.

\section{REFERENCES}

Anderson, S. D., Connolly, N. M., and Godfrey, S. (1971). Comparison of bronchoconstriction induced by cycling and running. Thorax, 26, 396.

Dawson, B., Horobin, G., Illsley, R., and Mitchell, R. (1969). A survey of childhood asthma in Aberdeen. Lancet, $1,827$.

Fitch, K. D., and Morton, A. R. (1971). Specificity of exercise in exercise-induced asthma. British Medical fournal, 4, 577.

Jones, R. H. T., and Jones, R. S. (1966). Ventilatory capacity in young adults with a history of asthma in childhood. British Medical fournal, 2, 976.

Jones, R. S., Buston, M. H., and Wharton, M. J. (1962). The effect of exercise on ventilatory function in the child with asthma. British fournal of Diseases of the Chest, 56, 78.

Jones, R. S., Wharton, M. J., and Buston, M. H. (1963). The place of physical exercise and bronchodilator drugs in the assessment of the asthmatic child. Archives of Disease in Childhood, 38, 539.

König, P., and Godfrey, S. (1973). Prevalence of exercise-induced bronchial lability in families of children with asthma. Archives of Disease in Childhood, 48, 513.

König, P., Godfrey, S., and Abrahamov, A. (1972). Exerciseinduced bronchial lability in children with a history of wheezy bronchitis. Archives of Disease in Childhood, 47, 578.

McNeill, R. S., Nairn, J. R., Millar, J. S., and Ingram, C. G. (1966). Exercise-induced asthma. Quarterly fournal of Medicine, 35, 55.

Williams, H., and McNicol, K. N. (1969). Prevalence, natural history, and relationship of wheezy bronchitis and asthma in children. An epidemiological study. British Medical fournal, 4, 321.

Correspondence to Dr. M. L. Burr, M.R.C. Epidemiology Unit, 4 Richmond Road, Cardiff CF2 3AS. 